\title{
Robotics to Enable Older Adults to Remain Living at Home
}

\author{
Alan J. Pearce, ${ }^{1,2}$ Brooke Adair, ${ }^{2}$ Kimberly Miller, ${ }^{2}$ Elizabeth Ozanne, ${ }^{3}$ \\ Catherine Said, ${ }^{2}$ Nick Santamaria, ${ }^{4}$ and Meg E. Morris ${ }^{2,5}$ \\ ${ }^{1}$ Cognitive and Exercise Neuroscience Unit, School of Psychology, Deakin University, Melbourne, VIC, Australia \\ ${ }^{2}$ Department of Physiotherapy, The University of Melbourne, Melbourne, VIC, Australia \\ ${ }^{3}$ Department of Social Work, The University of Melbourne, Melbourne, VIC, Australia \\ ${ }^{4}$ Department of Nursing, The University of Melbourne and Royal Melbourne Hospital, Melbourne, VIC, Australia \\ ${ }^{5}$ School of Allied Health, La Trobe University, Melbourne, VIC, Australia
}

Correspondence should be addressed to Meg E. Morris, m.morris@latrobe.edu.au

Received 30 April 2012; Revised 24 September 2012; Accepted 1 October 2012

Academic Editor: Roger A. Fielding

Copyright (C) 2012 Alan J. Pearce et al. This is an open access article distributed under the Creative Commons Attribution License, which permits unrestricted use, distribution, and reproduction in any medium, provided the original work is properly cited.

\begin{abstract}
Given the rapidly ageing population, interest is growing in robots to enable older people to remain living at home. We conducted a systematic review and critical evaluation of the scientific literature, from 1990 to the present, on the use of robots in aged care. The key research questions were as follows: (1) what is the range of robotic devices available to enable older people to remain mobile, independent, and safe? and, (2) what is the evidence demonstrating that robotic devices are effective in enabling independent living in community dwelling older people? Following database searches for relevant literature an initial yield of 161 articles was obtained. Titles and abstracts of articles were then reviewed by 2 independent people to determine suitability for inclusion. Fortytwo articles met the criteria for question 1 . Of these, 4 articles met the criteria for question 2. Results showed that robotics is currently available to assist older healthy people and people with disabilities to remain independent and to monitor their safety and social connectedness. Most studies were conducted in laboratories and hospital clinics. Currently limited evidence demonstrates that robots can be used to enable people to remain living at home, although this is an emerging smart technology that is rapidly evolving.
\end{abstract}

\section{Introduction}

Throughout the world rapid population ageing is occurring, with a large proportion of older adults preferring to stay living at home [1]. Most older people experience one to three chronic diseases [2] and, in very advanced age, frailty, disability, and social isolation are common. At the same time there are increasing demands on health service providers due to the low availability of home and community services, low uptake of e-health and smart technologies by healthcare professionals, and an ageing health workforce [3]. Although many older people express their desire to stay in the familiar social environment of their own home [4], many cannot do so due to impairments, immobility and social isolation. Many older people who live at home are at high risk of falls and injuries and report difficulty accessing health care services when they need them [5].
As previously discussed by Rowe and Kahn [6] the definition of successful aging requires three pillars. Firstly, there is a low probably of disease and/or disability from disease; secondly a high cognitive and physical functioning capacity; and three, the combination of the first two with an active engagement in life. In affecting successful aging, particularly with the nexus to an active engagement in life, there is a need for development of, and access to, smart technologies to monitor and maintain health and wellbeing, as well as to link older people with communities and healthcare professionals. One area where technology is rapidly advancing is robotics. Robots are now available that provide services such as home cleaning, appliance operation, and safety monitoring. These "service robots" can be excellent for monitoring, surveillance, and basic tasks of everyday living yet they lack artificial intelligence. Morris et al. [3] argued the need for "smart" robotic technologies that not only respond 
to an individual's needs, but can also learn and modify their behaviour based upon their owner's requirements. This is particularly the case for older individuals who would need to interact with their robot to maintain mobility, health, safety, and social connectedness.

Service robots currently include commercialised domestic robots, such as self-navigating vacuum cleaners and mops, known as Roomba and Scooba respectively [7]. Service robots also include "pet" or sociable robots, such as the Aibo robotic pet dog, Paro the robotic pet seal, and similar robotic animals that use "pet therapy" to assist older people to maintain mobility, and to keep active [8]. Service robots have also been developed for hospital settings. One example of this is the iWARD project in Germany [9] where modular designed robots have been adapted for different roles for independent living, health, and safety. They can also act in a team to service the needs of medical and other health professional staff such as for remote consultations and communication between staff in different wards.

The literature reveals some misconceptions about the potential for robotic interaction with humans. For example, popular opinion holds that robotic technologies are only applied to individuals when they are disabled [10]. However, there is a small yet increasing awareness that robotic technologies can also complement current health care service provision by monitoring older people within their home environment [11] and assisting them to mobilise safely and prevent falls [12]. Narrative literature reviews on the role of robotics in health care $[8,11-13]$ or social assistance robots [14] have previously been completed mainly speculating about the future of robotics in health. The aim of this systematic review was to identify specific evidence-based research answering questions to address the potential of robotic technologies to monitor older individuals' health and wellbeing and to assist with activities of daily living. Another aim was to review the extent of robotic technologies currently tested and used in the home environment for older individuals.

\section{Methods}

We identified two key questions for the systematic review of the literature addressing robotics and ageing in the home environment.

(1) What is the range of robotic devices available to enable older people to remain mobile, independent and safe?

(2) What is the evidence demonstrating that robotic devices are effective in enabling independent living in community dwelling older people?

Where possible, in each database, searches for all topics were limited to peer-reviewed publications between January 1990-February 2012, published in English. We included human participants aged 45 years and older, as it is generally accepted that many chronic conditions may have their onset from approximately this age onwards. This broader definition of older individuals' was adopted by the authors, defined by MESH heading definitions of "middle-aged" 4564 years, "aged" (65-79 years) and "aged $80+$ years" with the understanding that "older individuals" were a heterogeneous group. The authors also accepted the definition of a "home" setting as the individual's place of residence [15]. This included establishments providing residence and care for special needs, such as retirement villages and aged care facilities providing low care services, service integrated housing, and supported accommodation.

To answer question 1, randomised controlled studies, quasi-experimental studies, and comparative studies with and without concurrent controls, case-series and feasibility studies, systematic and general review articles, and government reports (where relevant to topic area) were included to identify available technologies. The following publications were excluded from the paper: narrative reviews, descriptive or narrative papers without presentation of data, limitedreview conference proceedings and abstracts, higher degree research theses (PhD/Masters), undergraduate research theses (Honours) and books.

To answer question 2, data extraction and quality assessments were predominantly performed on studies that met the criteria for question 1, however these studies were required to demonstrate that testing and/or data collection had been completed in a home (or simulated) environment.

Data base searches were limited to studies assessing humans and those published in English and included: Web of Science, Science Direct, MEDLINE, PSYCHINFO, SCOPUS, CINAHL, expanded version of the cumulative index to nursing and allied health by EBSCO, Australasian Medical Index, National Library for Health, Rehabilitation Research (USA), and TROVE.

Two independent, trained reviewers evaluated the title and abstracts of the yield articles against the decision rules inclusion criteria. The title of each article was scanned and the two reviewers independently excluded articles not related to the topic. The full texts of the articles were then obtained for data extraction, categorized according to National Health and Medical Research Council (NHMRC) guidelines on levels of evidence [16], and the quality of each article was assessed using the Downs and Black [52] quality appraisal tool. Downs and Black was specifically selected to assess the articles as it can be used for both experimental and quasiexperimental research designs. Two independent reviewers conducted data extraction and quality assessment for each article. Lack of agreement about inclusion of articles, data extracted, or grading against quality criteria was reconciled by mutual agreement.

\section{Results}

Figure 1 illustrates the breakdown of articles following the predetermined inclusion and exclusion criteria. The major reason for exclusion was that articles were descriptive and did not contain data providing evidence of effectiveness, feasibility, or validity. Table 1 shows the studies that have provided evidence of technologies assisting older people.

The yield of articles in response to question 1 showed that robotic technology is currently available to assist older 


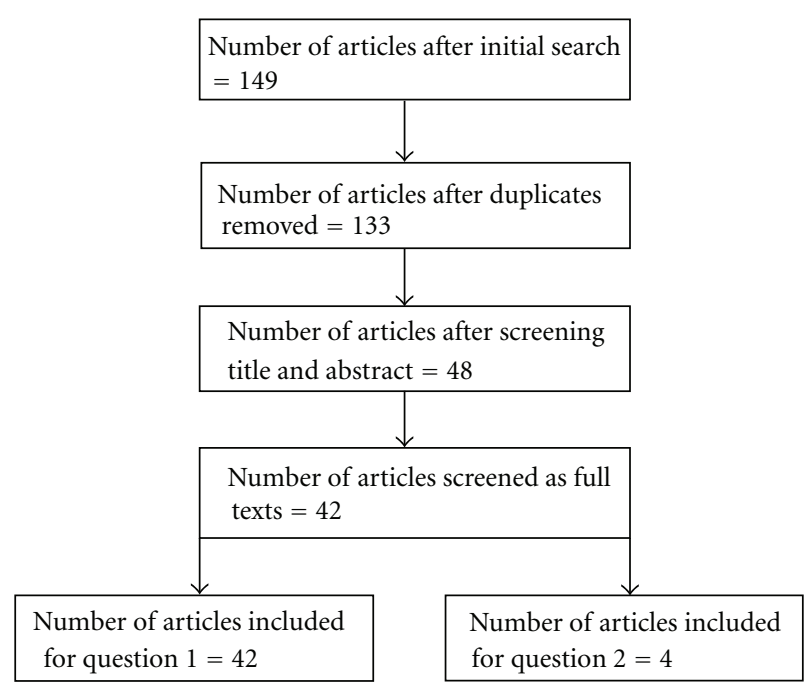

FIgURE 1: Yield of articles for the robotics literature.

people and people with physical disabilities. These were not "smart" robots per se, with no artificial intelligence interface, and the majority of these articles were lower limb "exoskeleton" technologies. Robotic exoskeletons are fitted to the outside of the limbs, rather than being internally fixed using surgical methods and supplies at the energy (or part of the energy) for limb movement. The "Lokomat" was the most widely tested robotic exoskeleton for the lower limbs $[25,27,29,33,37,48,49]$ to trial its suitability as a supportive structure for walking. Other technologies to assist with walking and mobility included robotic walkers and robotic guidance systems $[30,38]$. These systems, such as the "Guido", are extensions on the non-motorised walker frames, where the individual can control the speed of locomotion but also obtain environmental feedback, via sensors, to assist in obstacle avoidance and in navigating through doorways.

Upper limb technologies included both upper limb exoskeleton systems to guide arm movements and haptic visuomotor feedback systems to assist in compensation for disorders of sensation and visual impairment. The "MITMANUS", a visuomotor guidance system, was the most utilised of the upper limb robotic systems, particularly for people who were recovering from stroke $[17,19,21,24,35]$

Table 2 shows the articles that met the inclusion criteria for question 2. To date, four investigations have tested robots within a home, residential care setting, or simulated home environment. Generally, these studies demonstrated that robots are able to help older people with mobility issues around the home environment. However, this data presented was only low to moderate in terms of their level of evidence and research quality [52]. Shimada et al. [40] investigated the effectiveness of a lower limb exoskeleton device using a pre-post single group design in older healthy females within an independent home living facility. Unlike other lower limb robots, such as the Lokomat which is a relatively large driven gait orthosis that automates locomotion therapy, the exoskeleton technology in this study was smaller and more compact. This study reported improvements in walking speed and reduced energy expenditure (due to fitness gains) following 3 months of 2 sessions (90 minutes duration) per week of assisted walking using the exoskeleton technology with elderly females. Spenko et al. [28] investigated the effectiveness of a robotic personal mobility aid with sensors to guide elderly ambulatory individuals away from obstacles. Analysis of the effectiveness of the technology was difficult to interpret as only descriptive data were presented in the paper. Saeki et al. [32] presented a case study describing the use of an upper limb robotic trainer in an elderly woman two years post hemiparesis. Improvements in motor function were reported in musculature of the proximal arm compared to the distal hand and alterations in cortical representation maps of the affected area were suggestive of plastic adaptations. However, these cortical representation changes were not correlated with changes in movement performance of the hemi paretic upper limb. Finally, a recent study by Carlson and Demiris [51] demonstrated improvements in wheelchair mobility when combined with a robotic interface (collaborative control) compared to when participants had to control the wheelchair manually without robotic assistance. Moreover these authors showed, via self-reported questionnaire, that participants found manoeuvering the wheelchair less mentally demanding during collaborative control.

\section{Discussion}

This systematic review has highlighted that robotics is still an emerging field in terms of its application to health and rehabilitation for community dwelling older people. Despite these studies being of a lower design quality, the evidence to date shows that robotics research is used widely in engineering laboratories and, to a lesser extent, in clinical settings. Only a very small number of controlled clinical trials evaluated the effects of implementing robotic technology in the home for the purposes of potentially assisting with daily living activities, home care, home maintenance and housework, security, safety, falls detection, or social interaction. Moreover, none of the studies on robotics presented costing of the devices, discussed safety concerns to the user, whether the devices could be mass produced, or social issues such as acceptance by older people in their home environment.

It was also notable that the studies in this paper focussed on application of robotic technologies for purposes of movement rehabilitation in people who had impairments and disabilities arising from conditions such as arthritis, back pain, balance impairment, stroke, or spinal cord injury. To date no studies have objectively measured the potential application of robotic technologies as monitoring devices in the home setting. Potentially artificial intelligence could be used to measure the health status of their "owner," provide reminders for specific medications to be taken; or provide contingency procedures in the case of an adverse event such as a slip, trip, or fall.

One study in this paper demonstrated an increased exercise capacity when healthy older participants utilised a robotic exoskeleton for walking training in a "home" setting [40]; however as the study was limited to only 


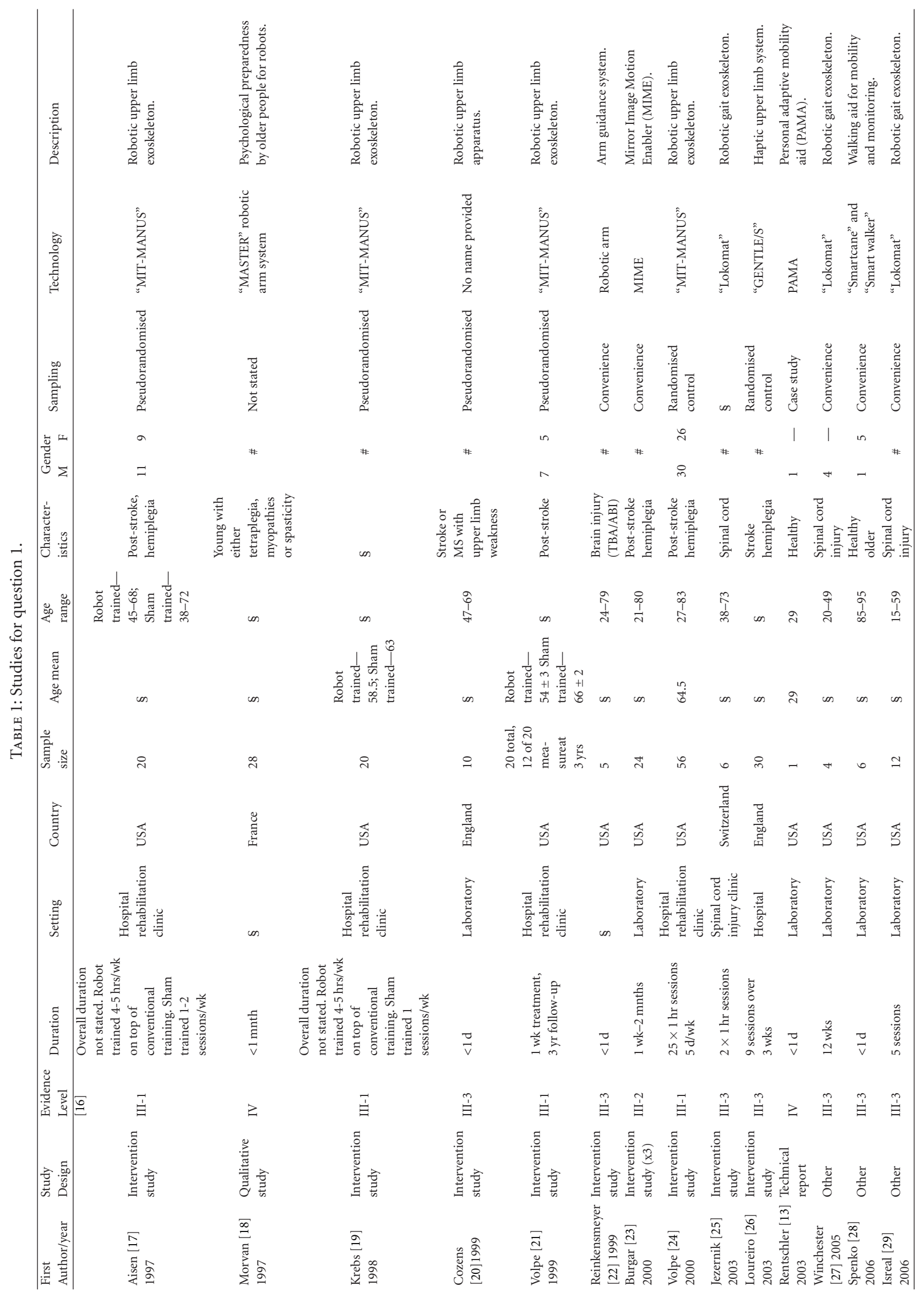




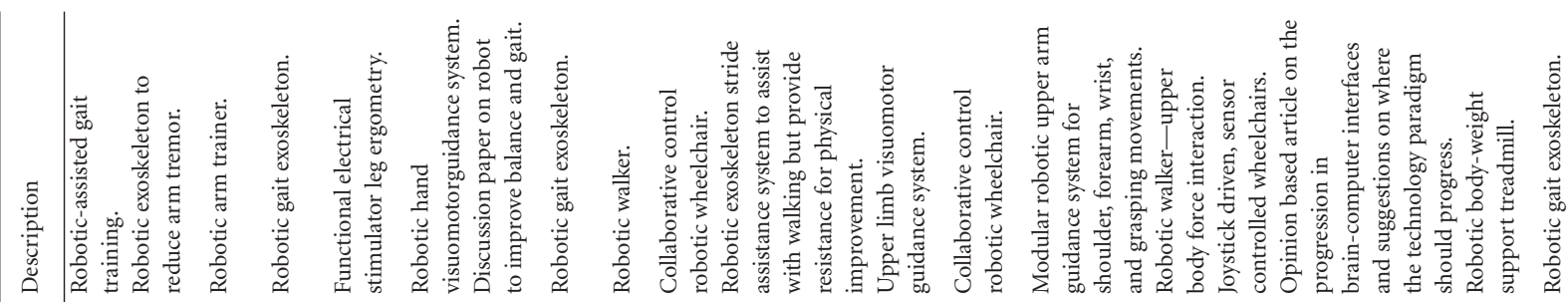

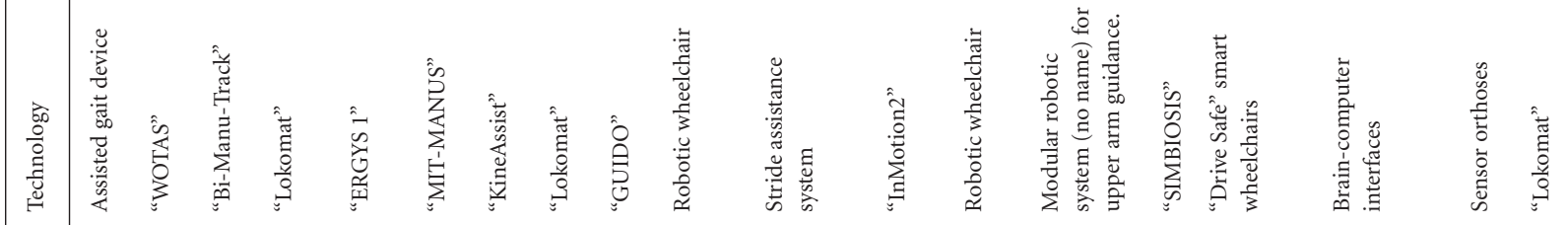

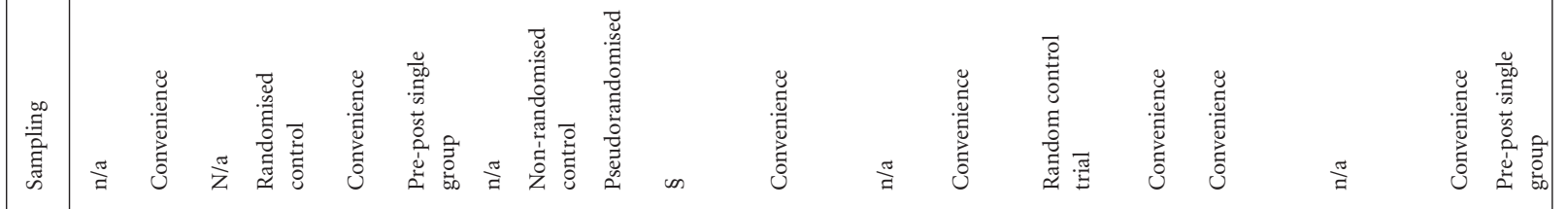

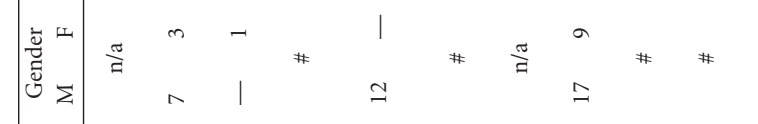

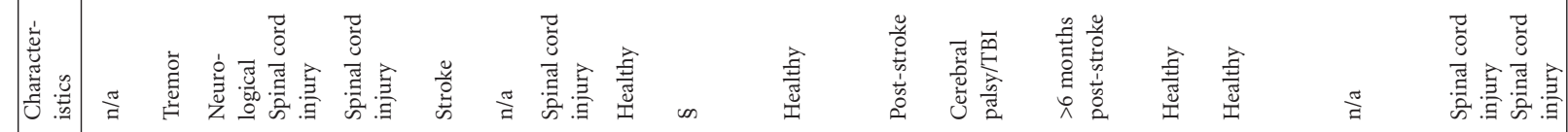

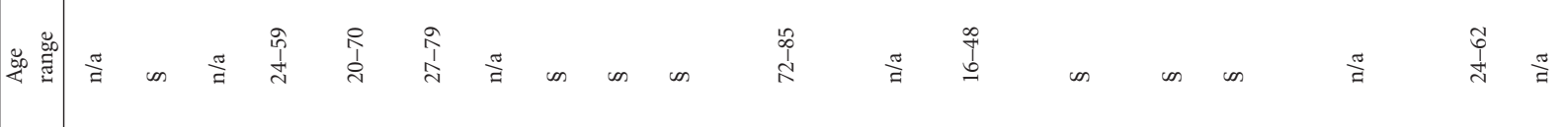

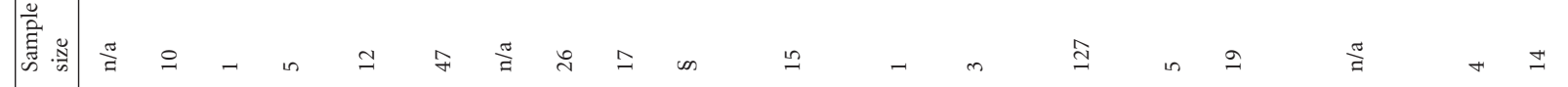

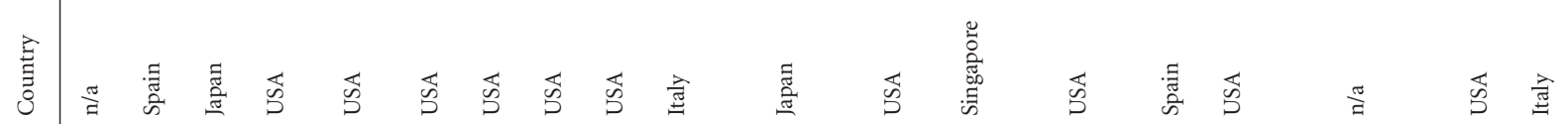

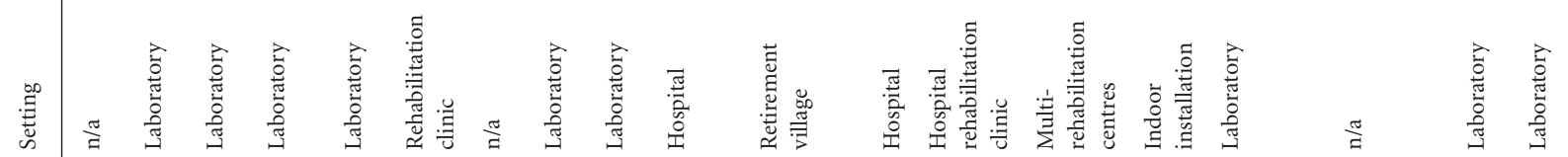

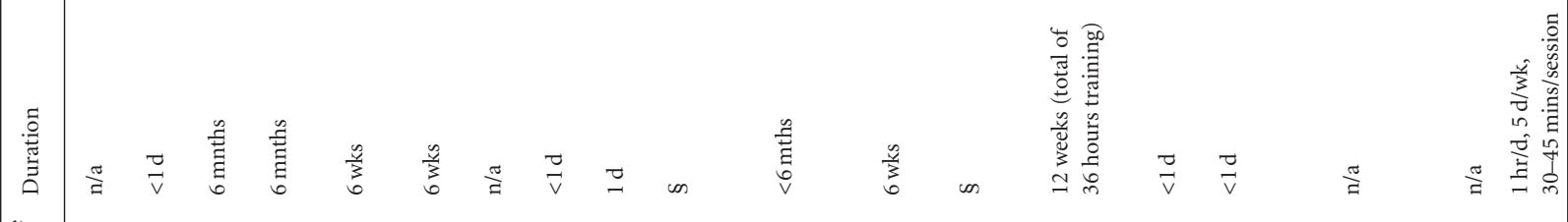

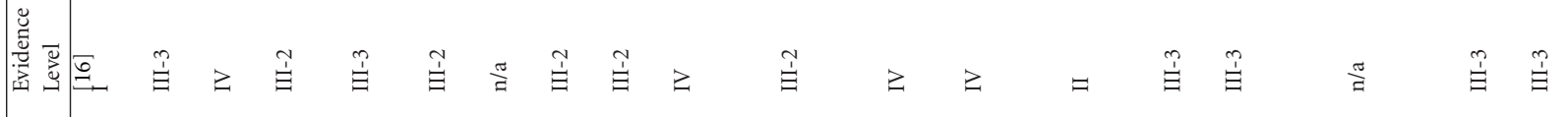

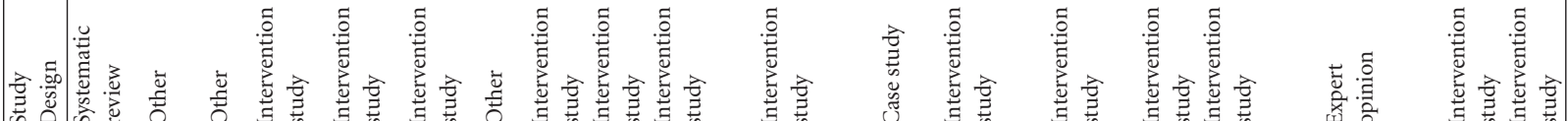

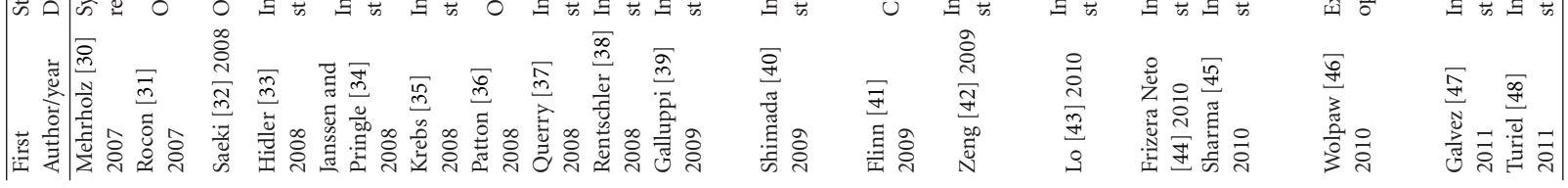




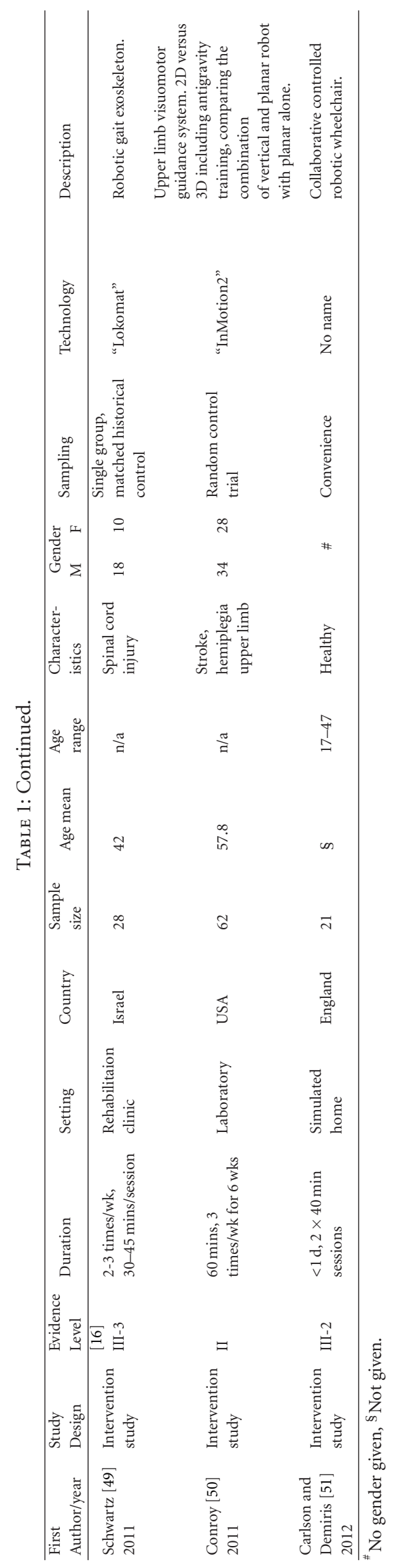




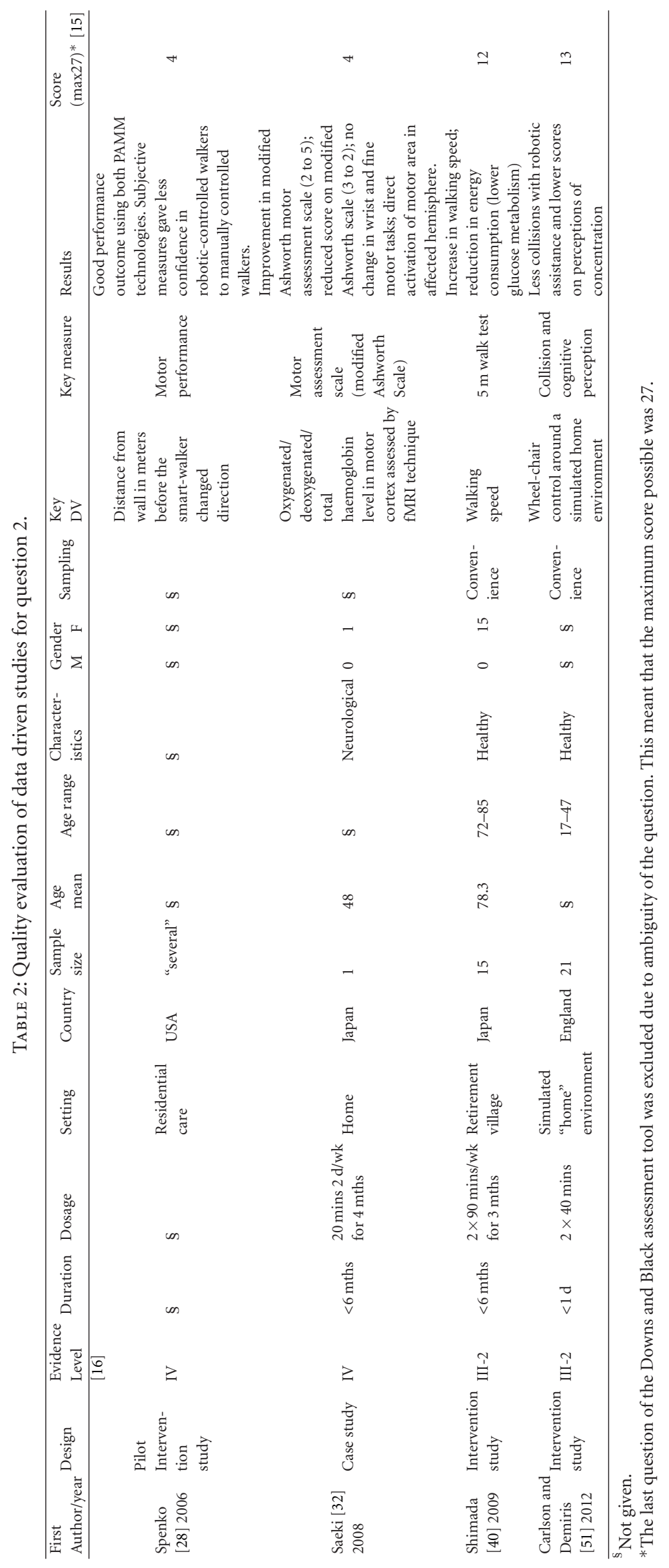


one group, with no direct comparison to an age-matched control group who participated in the walking program without the exoskeleton, it is difficult to rigorously evaluate the effectiveness of the use of the robotic exoskeleton in this study. Moreover, follow-up data measures were not taken, therefore it is not possible to ascertain the long-term effectiveness of the technology in assisting in maintaining independence.

However, this paper has demonstrated that applications of robotic technologies have progressed much further than what the general public perceive robots are capable of undertaking. Robotic technology studies, despite being methodologically weak [52], have demonstrated capability of functional improvements following loss of function in upper and lower limbs, or to assist with mobility in indoor environments. The range of the robotic technologies presented in in Table 2 show that the technology is now progressing to the point that that home trials of these different robotic technologies will be undertaken in the near future.

A limitation of this review was that non-English language studies were excluded. Therefore it is possible that studies of testing robotics in the home environment have been completed, but were not included in this paper as they were published in languages other than English. A second limitation of this review was the decision by the authors to exclude robotic interventions for uses relating to cognitive decline/successful brain aging. Indeed, recent reviews have discussed the use of robotics for cognitive healthcare in the elderly [3]; however, the primary aim of this paper was to review evidence for robotics in addressing physical mobility to reduce disability and loss of independence in the home. Further, although outside the scope of this review and thus also excluded was the emergence of nanotechnology. It is plausible to suggest that progress in nanotechnology research (also known as nanorobotics) [53] could potentially reduce hazards in the home. Robotics will improve, in a number of different directions, to the point of assisting older people to live independently and safely in their homes, and enjoy excellent quality of life in their communities.

The recently released (April 2012) Living Longer. Living Better Report from the Australian Federal Government [54] in response to the Productivity Commission's Report on Care of Older Australians [55] recommends the major expansion of home care supportive services, although these are largely conceptualized as intensive case management services. However, the aged housing and care industry in Australia is moving ahead with the rapid take up of new technologies to assist older people to live more independently at home and in supported accommodation in association with the rollout of a new broadband network nationally [55].

Robotics are perhaps one of the newest technology areas to have entered the home care market, being previously largely developed for application in heavy industry and acute health. Looking forward, however, the potential for robotic application in the home is wide open. Some of the major barriers relate to cost of development, the incorporation of artificial intelligence in new design applications, and the encouragement of greater interdisciplinary convergence between the many research fields now involved in the development of new robotic technologies. At this point in time in Australia, progress on home grown robotic applications is limited, given the substantial infrastructure required in the start-up phase [56].

In light of the research reviewed, a number of key recommendations can be provided as follows:

4.1. Applying Research into Home Environments. The evidence from the current systematic review has clearly demonstrated that robotics research needs to be conducted in the home environment. To date, only four studies have attempted to conduct research within the home environment $[28,32,40,51]$. These studies have demonstrated positive outcomes, providing a good rationale to take robotics into environments outside of laboratories or hospital clinics.

4.2. Diversifying Robotics. The majority of robotic technology studies found in the current review were directed at movement rehabilitation. However, for the elderly population, healthy living includes prompting and reminding for effective monitoring. Development of robotic technologies should include technologies that can provide gentle reminders for medications, continually scan the environment to ensure no falls have taken place, and have a protocol in place to advise relevant authorities if an incident has occurred. Similarly, robotics has the potential to allow for social connectedness by providing company for elderly people living alone, or to serve as interfaces for connecting with family and friends using existing technologies (e.g., Skype).

4.3. Reducing Costs. The final recommendation would be to investigate ways of reducing the costs of technologies. As shown in this paper, robotic technologies are still in development and trial phases. It would be anticipated that with commercial development and mass production, these costs would reduce significantly. However, at the present time costs appear to be a barrier towards broad adoption of robots in the home environment.

In conclusion, this systematic review has shown that robotic technologies have the potential to assist older people and people with disabilities to remain mobile and to live safe and healthy lives at home. Further research and training of the heath and disability workforces is needed to the adoption of robotics as an effective, routine, and practical option within the home environment. The evidence demonstrates that robots already exist to assist with movements, obstacleavoidance, and functional rehabilitation, but require further development to realise their full potential for safety monitoring, falls, and social connectedness. Future robot design needs to consider development from a different perspective, considering not only assisted mobility, but also interfacing artificial intelligence for interaction with older individuals, to monitor their health, provide medication prompts, encourage exercise, and provide them with confidence to maintain independent living. 


\section{Conflict of Interests}

The authors declare that they have no conflict of interests.

\section{Acknowledgments}

This work was supported by a Grant from the Institute for a Broadband-Enabled Society (IBES). The authors would like to thank Ms. Erin Hickingbotham for her assistance in preliminary data collection.

\section{References}

[1] United Nations, World Population Prospects: The 2006 Revision, United Nations, New York, NY, USA, 2007.

[2] Chronic Diseases, Australian Institute of Health and Welfare, http://www.aihw.gov.au/chronic-diseases/.

[3] M. E. Morris, E. Ozanne, K. Miller, N. Santamaria, A. J. Pearce, C. Said et al., Smart Technologies for Older People: A Systematic Literature Review of Smart Technologies That Promote Health and Wellbeing of Older People Living at Home, Institute for a Broadband-Enabled Socity, Melbourne, Australia, 2012.

[4] M. A. Groves and V. F. Wilson, "To move or not to move? Factors influencing the housing choice of elderly persons," Journal of Housing for the Elderly, vol. 10, pp. 33-47, 1992.

[5] A. Shumway-Cook, A. M. Ciol, J. Hoffman, J. B. Dudgeon, K. Yorkston, and L. Chan, "Falls in the medicare population: incidence, associated factors, and on health care," Physical Therapy, vol. 89, no. 4, pp. 324-332, 2009.

[6] J. W. Rowe and R. L. Kahn, "Successful aging," The Gerontologist, vol. 37, no. 4, pp. 433-440, 1997.

[7] C. Kuzma, "The human touch," Science and Spirit, vol. 4, pp. 15-17, 2006.

[8] L. Carelli, A. Gaggioli, G. Pioggia, F. de Rossi, and G. Riva, "Affective robot for elderly assistance," Studies in Health Technology and Informatics, vol. 144, pp. 44-49, 2009.

[9] S. Thiel, D. Häbe, and M. Block, "Co-operative robot teams in a hospital environment," in Proceedings of the IEEE International Conference on Intelligent Computing and Intelligent Systems (ICIS'09), pp. 843-847, Shanghai, China, November 2009.

[10] E. Broadbent, I. H. Kuo, Y. I. Lee et al., "Attitudes and reactions to a healthcare robot," Telemedicine Journal and E-Health, vol. 16, no. 5, pp. 608-613, 2010.

[11] C. Ray, F. Mondada, and R. Siegwart, "What do people expect from robots?" in Proceedings of the IEEE/RSJ International Conference on Intelligent Robots and Systems (IROS'08), pp. 3816-3821, Nice, France, September 2008.

[12] M. Kassler, "Robotics for health care: a review of the literature," Robotica, vol. 11, no. 6, pp. 495-516, 1993.

[13] A. J. Rentschler, R. A. Cooper, B. Blasch, and M. L. Boninger, "Intelligent walkers for the elderly: performance and safety testing of VA-PAMAID robotic walker," Journal of Rehabilitation Research and Development, vol. 40, no. 5, pp. 423-431, 2003.

[14] J. Broekens, M. Herrink, and H. Rosendal, "Assistive social robots in elderly care: a review," Gerontechnology, vol. 8, no. 2, pp. 94-103, 2009.

[15] Merriam-Webster Dictionary (Online), 2011, http://www .merriam-webster.com/netdict.htm.
[16] NHMRC, NHMRC levels of evidence and grades for recommendations for developers of guidelines, 2009, https:// www.nhmrc.gov.au/_files_nhmrc/file/guidelines/developers/ nhmrc_levels_grades_evidence_120423.pdf.

[17] M. L. Aisen, H. I. Krebs, N. Hogan, F. McDowell, and B. T. Volpe, "The effect of robot-assisted therapy and rehabilitative training on motor recovery following stroke," Archives of Neurology, vol. 54, no. 4, pp. 443-446, 1997.

[18] J. S. Morvan, J. P. Guichard, and V. Torossian, “Technical aids for the physically handicapped: a psychological study of the master robot," International Journal of Rehabilitation Research, vol. 20, no. 2, pp. 193-197, 1997.

[19] H. I. Krebs, N. Hogan, M. L. Aisen, and B. T. Volpe, "Robotaided neurorehabilitation," IEEE Transactions on Rehabilitation Engineering, vol. 6, no. 1, pp. 75-87, 1998.

[20] J. A. Cozens, "Robotic assistance of an active upper limb exercise in neurologically impaired patients," IEEE Transactions on Rehabilitation Engineering, vol. 7, no. 2, pp. 254-256, 1999.

[21] B. T. Volpe, H. I. Krebs, N. Hogan, L. Edelsteinn, C. M. Diels, and M. L. Aisen, "Robot training enhanced motor outcome in patients with stroke maintained over 3 years," Neurology, vol. 53, no. 8, pp. 1874-1876, 1999.

[22] D. J. Reinkensmeyer, J. P. A. Dewald, and W. Z. Rymer, "Guidance-based quantification of arm impairment following brain injury: a pilot study," IEEE Transactions on Rehabilitation Engineering, vol. 7, no. 1, pp. 1-11, 1999.

[23] C. G. Burgar, P. S. Lum, P. C. Shor, and H. F. M. van der Loos, "Development of robots for rehabilitation therapy: the Palo Alto VA/Stanford experience," Journal of Rehabilitation Research and Development, vol. 37, no. 6, pp. 663-673, 2000.

[24] B. T. Volpe, H. I. Krebs, N. Hogan, L. Edelstein, C. Diels, and M. Aisen, "A novel approach to stroke rehabilitation: robotaided sensorimotor stimulation," Neurology, vol. 54, no. 10, pp. 1938-1944, 2000.

[25] S. Jezernik, R. Schärer, G. Colombo, and M. Morari, "Adaptive robotic rehabilitation of locomotion: a clinical study in spinally injured individuals," Spinal Cord, vol. 41, no. 12, pp. 657-666, 2003.

[26] R. Loureiro, F. Amirabdollahian, M. Topping, B. Driessen, and W. Harwin, "Upper limb robot mediated stroke therapyGENTLE/s approach," Autonomous Robots, vol. 15, no. 1, pp. 35-51, 2003.

[27] P. Winchester, R. McColl, R. Querry et al., "Changes in supraspinal activation patterns following robotic locomotor therapy in motor-incomplete spinal cord injury," Neurorehabilitation and Neural Repair, vol. 19, no. 4, pp. 313-324, 2005.

[28] M. Spenko, H. Yu, and S. Dubowsky, "Robotic personal aids for mobility and monitoring for the elderly," IEEE Transactions on Neural Systems and Rehabilitation Engineering, vol. 14, no. 3, pp. 344-351, 2006.

[29] J. F. Israel, D. D. Campbell, J. H. Kahn, and T. G. Hornby, "Metabolic costs and muscle activity patterns during roboticand therapist-assisted treadmill walking in individuals with incomplete spinal cord injury," Physical Therapy, vol. 86, no. 11, pp. 1466-1478, 2006.

[30] J. Mehrholz, C. Werner, J. Kugler, and M. Pohl, "Electromechanical-assisted training for walking after stroke," Cochrane Database of Systematic Reviews, no. 4, Article ID CD006185, 2007.

[31] E. Rocon, J. M. Belda-Lois, A. F. Ruiz, M. Manto, J. C. Moreno, and J. L. Pons, "Design and validation of a rehabilitation robotic exoskeleton for tremor assessment and suppression," 
IEEE Transactions on Neural Systems and Rehabilitation Engineering, vol. 15, no. 1, pp. 367-378, 2007.

[32] S. Saeki, Y. Matsushima, and K. Hachisuka, "Cortical activation during robotic therapy for a severely affected arm in a chronic stroke patient: a case report," Journal of UOEH, vol. 30, no. 2, pp. 159-165, 2008.

[33] J. Hidler, L. F. Hamm, A. Lichy, and S. L. Groah, "Automating activity-based interventions: the role of robotics," Journal of Rehabilitation Research and Development, vol. 45, no. 2, pp. 337-344, 2008.

[34] T. W. J. Janssen and D. D. Pringle, "Effects of modified electrical stimulation-induced leg cycle ergometer training for individuals with spinal cord injury," Journal of Rehabilitation Research and Development, vol. 45, no. 6, pp. 819-830, 2008.

[35] H. I. Krebs, S. Mernoff, S. E. Fasoli, R. Hughes, J. Stein, and N. Hogan, "A comparison of functional and impairment-based robotic training in severe to moderate chronic stroke: a pilot study," NeuroRehabilitation, vol. 23, no. 1, pp. 81-87, 2008.

[36] J. Patton, D. A. Brown, M. Peshkin et al., "KineAssist: design and development of a robotic overground gait and balance therapy device," Topics in Stroke Rehabilitation, vol. 15, no. 2, pp. 131-139, 2008.

[37] R. G. Querry, F. Pacheco, T. Annaswamy, L. Goetz, P. K. Winchester, and K. E. Tansey, "Synchronous stimulation and monitoring of soleus $\mathrm{H}$ reflex during robotic body weightsupported ambulation in subjects with spinal cord injury," Journal of Rehabilitation Research and Development, vol. 45, no. 1, pp. 175-186, 2008.

[38] A. J. Rentschler, R. Simpson, R. A. Cooper, and M. L. Boninger, "Clinical evaluation of Guido robotic walker," Journal of Rehabilitation Research and Development, vol. 45, no. 9, pp. 1281-1294, 2008.

[39] F. Galluppi, C. Urdiales, I. Sanchez-Tato, F. Sandoval, and M. O. Belardinelli, "A study on a shared control navigation system: human/robot collaboration for assisting people in mobility," Cognitive Processing, vol. 10, supplement 2, pp. S215-S218, 2009.

[40] H. Shimada, T. Hirata, Y. Kimura et al., "Effects of a robotic walking exercise on walking performance in communitydwelling elderly adults," Geriatrics \& Gerontology International, vol. 9, no. 4, pp. 372-381, 2009.

[41] N. A. Flinn, J. L. Smith, C. J. Tripp, and M. W. White, "Effects of robotic-aided rehabilitation on recovery of upper extremity function in chronic stroke: a single case study," Occupational Therapy International, vol. 16, no. 3-4, pp. 232-243, 2009.

[42] Q. Zeng, E. Burdet, and C. L. Teo, "Evaluation of a collaborative wheelchair system in cerebral palsy and traumatic brain injury users," Neurorehabilitation and Neural Repair, vol. 23, no. 5, pp. 494-504, 2009.

[43] A. C. Lo, P. D. Guarino, L. G. Richards et al., "Robot-assisted therapy for long-term upper-limb impairment after stroke," The New England Journal of Medicine, vol. 362, no. 19, pp. 1772-1783, 2010.

[44] A. Frizera Neto, J. A. Gallego, E. Rocon, J. L. Pons, and R. Ceres, "Extraction of user's navigation commands from upper body force interaction in walker assisted gait," BioMedical Engineering Online, vol. 9, article 37, 2010.

[45] V. Sharma, R. Simpson, E. Lopresti, and M. Schmeler, "Evaluation of semiautonomous navigation assistance system for power wheelchairs with blindfolded nondisabled individuals," Journal of Rehabilitation Research and Development, vol. 47, no. 9, pp. 877-890, 2010.
[46] J. R. Wolpaw, "Brain-computer interface research comes of age: traditional assumptions meet emerging realities," Journal of Motor Behavior, vol. 42, no. 6, pp. 351-353, 2010.

[47] J. A. Galvez, A. Budovitch, S. J. Harkema, and D. J. Reinkensmeyer, "Trainer variability during step training after spinal cord injury: implications for robotic gait-training device design," Journal of Rehabilitation Research and Development, vol. 48, no. 2, pp. 147-160, 2011.

[48] M. Turiel, S. Sitia, S. Cicala et al., "Robotic treadmill training improves cardiovascular function in spinal cord injury patients," International Journal of Cardiology, vol. 149, no. 3, pp. 323-329, 2011.

[49] I. Schwartz, A. Sajina, M. Neeb, I. Fisher, M. Katz-Luerer, and Z. Meiner, "Locomotor training using a robotic device in patients with subacute spinal cord injury," Spinal Cord, vol. 49, pp. 1062-1067, 2011.

[50] S. S. Conroy, J. Whitall, L. Dipietro et al., "Effect of gravity on robot-assisted motor training after chronic stroke: a randomized trial," Archives of Physical Medicine and Rehabilitation, vol. 92, no. 11, pp. 1754-1761, 2011.

[51] T. Carlson and Y. Demiris, "Collaborative control for a robotic wheelchair: evaluation of performance, attention, and workload," IEEE Transactions on Systems, Man, and Cybernetics B, vol. 42, no. 3, Article ID Article number6135817, pp. 876-888, 2012.

[52] S. H. Downs and N. Black, "The feasibility of creating a checklist for the assessment of the methodological quality both of randomised and non-randomised studies of health care interventions," Journal of Epidemiology and Community Health, vol. 52, no. 6, pp. 377-384, 1998.

[53] R. Frietas Jr., "Comprehensive nanorobotic control of human morbidity and aging," in The Future of Aging, G. M. Fahey, M. D. West, L. S. Coles, and S. B. Harris, Eds., chapter 23, Spinger, Dordrecht, The Netherlands, 2010.

[54] Department of Health and Ageing, Living longer, living better, 2012, http://www.health.gov.au/internet/main/ publishing.nsf/Content/ageing-hacc-living.htm.

[55] Department of Broadband, Communications and the Digital Economy, National digital economy strategy: leveraging the national broadband network to drive Australia's digital productivity, 2011, http://www.nbn.gov.au/files/2011/05/ National_Digital_Economy_Strategy.pdf.

[56] Academy of Technological Sciences and Engineering, Smart technology for healthy longevity, 2010, http://www.atse.org .au/news/featured-articles/155-smart-tech-for-healthlongevity/. 


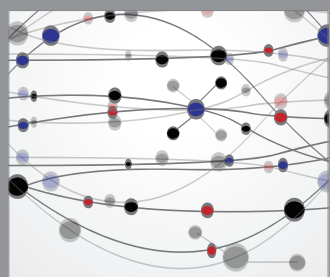

The Scientific World Journal
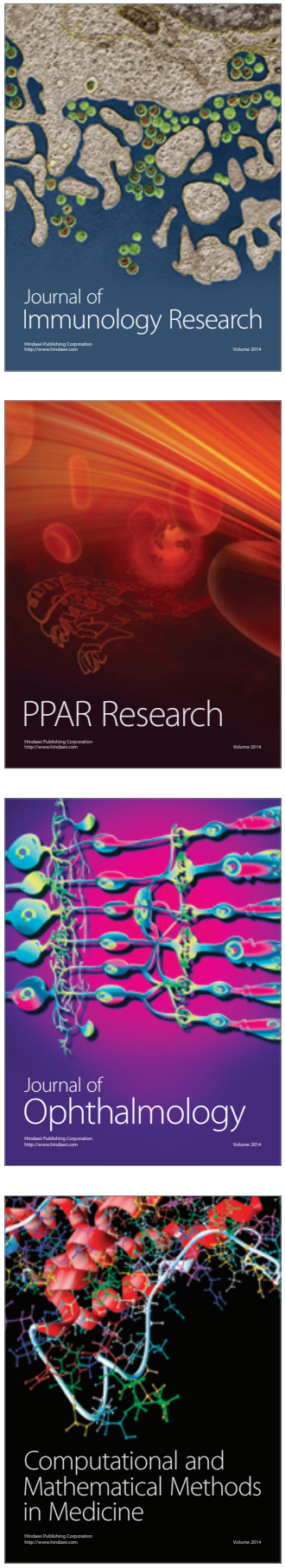

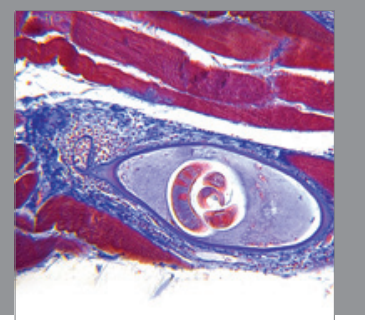

Gastroenterology

Research and Practice
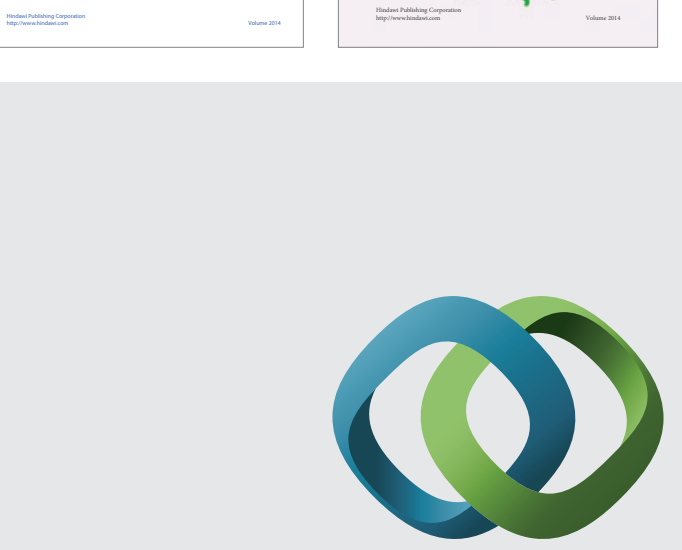

\section{Hindawi}

Submit your manuscripts at

http://www.hindawi.com
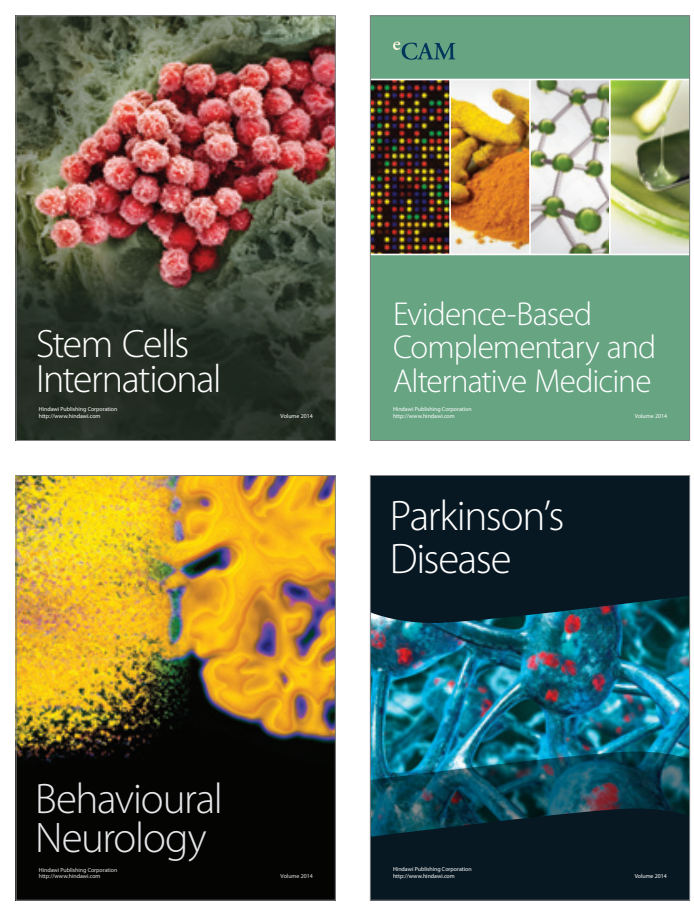

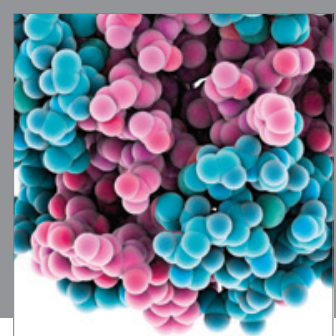

Journal of
Diabetes Research

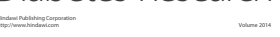

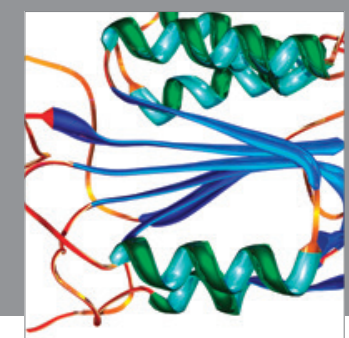

Disease Markers
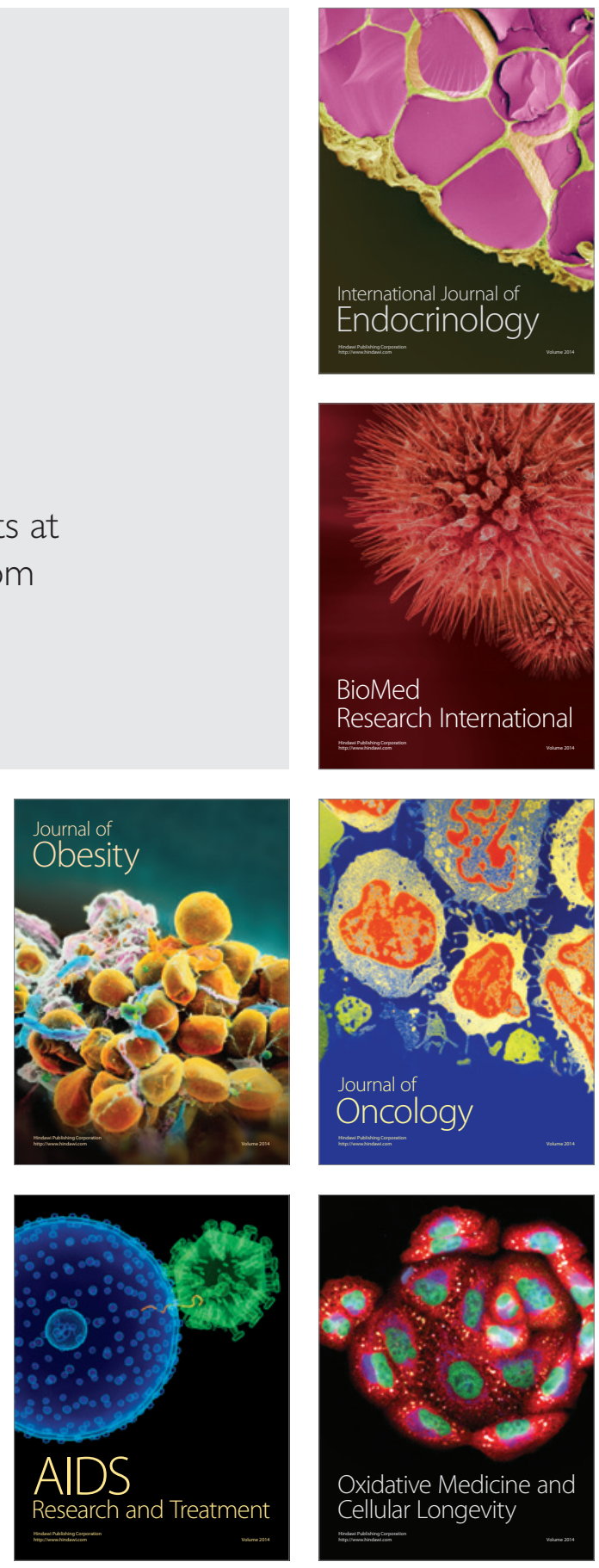